\title{
Gray matter alteration in medication overuse headache: a coordinates-based activation likelihood estimation meta-analysis
}

\author{
Wenjia Chen ${ }^{1,2} \cdot \mathrm{Hui} \mathrm{Li}^{1,2} \oplus \cdot$ Xiaoyan $\mathrm{Hou}^{3} \cdot \mathrm{Xize} \mathrm{Jia}^{4}$
}

Accepted: 11 January 2022 / Published online: 10 February 2022

(c) The Author(s) 2022

\begin{abstract}
Medication overuse headache (MOH) is a prevalent secondary headache, bringing heavy economic burden and neuropsychological damage. Neuroimaging studies on the disease reported divergent results. To merge the reported neuroimaging alterations in $\mathrm{MOH}$ patients and explore a pathophysiological mechanism of this disorder. A meta-analytic activation likelihood estimation (ALE) analysis method was used. We systematically searched English and Chinese databases for both morphological and functional neuroimaging studies published before Nov 18, 2021. Reported altered brain regions and the stereotactic coordinates of their peaks were extracted and pooled by GingerALE using Gaussian probability distribution into brain maps, illustrating converged regions of alteration among studies. We identified 927 articles, of which five studies on gray matter changes, using voxel-based morphometry (VBM) were eventually included for ALE analysis, with 344 subjects and 54 coordinates put into GingerALE. No functional magnetic resonance imaging (fMRI) or positron emission topography (PET) studies were included for pooling. Compared with healthy controls (HCs), MOH featured increased gray matter density in midbrain, striatum, cingulate, inferior parietal cortex and cerebellum $(P<0.001$ uncorrected), whereas decreased gray matter density in orbitofrontal cortex $(P<0.05$, family-wise error), frontal, insular and parietal cortices $(P<0.001$ uncorrected). Withdrawal of analgesics led to decreased gray matter density in superior temporal gyrus, cuneus, midbrain and cerebellum $(P<0.001$ uncorrected $)$. This meta-analysis confirmed that medication overuse headache is associated with morphologic alteration in the reward system, the prefrontal cortex and a reversible modification in the pain network. Further functional imaging paradigms and longitudinal studies are required for a more definite conclusion and a causal mechanism.
\end{abstract}

Keywords Medication overuse headache $\cdot$ ALE $\cdot$ Gray matter $\cdot$ VBM $\cdot$ Detoxification

\section{Hui Li}

lihuitcm@126.com

1 Headache Sub-department of Neurology Department, Second Affiliated Hospital of Guangzhou University of Chinese Medicine/Guangdong Provincial Hospital of Chines Medicine, Guangzhou, People's Republic of China

2 Research Group of Standardization of Chinese Medicine, Second Affiliated Hospital of Guangzhou University of Chinese Medicine/Guangdong Provincial Hospital of Chines Medicine, Guangzhou, People's Republic of China

3 Radiology Department, Second Affiliated Hospital of Guangzhou University of Chinese Medicine/Guangdong Provincial Hospital of Chinese Medicine, Guangzhou, People's Republic of China

4 Department of Psychology Science, Hangzhou Normal University, Hangzhou, People's Republic of China

\section{Introduction}

Medication overuse headache (MOH) is a chronic headache that occurs on 15 or more days per month for over three months with overuse of acute or symptomatic headache medications for more than 10 or 15 days per month depending on overdosed medication (Headache Classification Committee of the International Headache Society, 2018). It was reported $\mathrm{MOH}$ patients worldwide exceeded 800 million in 2017 (James et al., 2018). As much as 4\% of the worldwide population is overusing painkillers, of which about $1 \%$ suffer from overdose headache (Diener \& Limmroth, 2004). About 53\% of chronic migraine (CM) patients repeatedly overuse analgesics (Westergaard et al., 2014). MOH can be caused by overdosing ergots, triptan, barbiturates, opioids, nonsteroidal anti-inflammatory drugs (NSAIDs, e.g. aspirin, acetaminophen, etc.), or a combination of these drugs. The harm of MOH is not restricted to persistent pain and heavy 
economic burden, but also the toxicity of the drug itself. Excessive ergotamine can cause sensory nerve damage, central cognitive function damage, and decreased ductility of the craniocerebral artery wall, causing psychological dysfunction (such as severe pain) (Cevoli et al., 2017). Long time exposure to triptans in animals enhanced calcitonin gene-related peptide and nitric oxide system activity, resulting in persistent allodynia (De Felice et al., 2009).

The pathogenesis of $\mathrm{MOH}$, which remains elusive, involves central sensitization(Ayzenberg et al., 2006), dysfunction of the endogenous serotonin system dysfunction(Reuter et al., 2004), etc. In the past decade, multiple scholars explored with magnetic resonance imaging (MRI) the neuroimaging changes of MOH but obtained divergent results. Lai et al. (Lai et al., 2016) reported that MOH patients, compared with healthy controls (HCs), displayed gray matter atrophy in the rectal gyrus, inferior frontal gyrus, middle frontal gyrus, and precuneus. While Mehnert et al. (Mehnert et al., 2018) discovered that MOH related gray matter atrophy located in the medial orbital gyrus, hippocampus, inferior frontal gyrus, and precuneus. However, several researchers did not find gray matter changes in $\mathrm{MOH}$ relative to HCs (Beckmann et al., 2018; Chanraud et al., 2014). Disparity among studies is apparent.

The purpose of this study was to explore a pattern of common neuroimaging change in $\mathrm{MOH}$ patients, with the help of a novel meta-analytic activation likelihood estimation (ALE) algorithm (Eickhoff et al., 2009, 2012; Turkeltaub et al., 2012), by merging the reported neuroimaging abnormalities from different studies, shedding light on a neurophysiologic mechanism of this disorder.

\section{Methods}

\section{Literature search and selection}

In this study, we adopted the meta-analysis definition embraced by the Cochrane Collaboration and followed the Preferred Reporting Items for Systematic Reviews and MetaAnalyses (PRISMA) Statement guidelines. A systematic search was carried out to thoroughly include all relevant studies on $\mathrm{MOH}$ published before Nov. 18, 2021, using all available imaging techniques, including MRI, blood-oxygenlevel dependent (BOLD)-functional MRI (fMRI) or positron emission tomography (PET), that are compatible for ALE. The query terms were as follows:

(1) analgesic overuse OR medication overuse OR medication overuse headache(MeSH term)

(2) headache or migraine(in title or abstract)

(3) positron emission tomography or PET(in title or abstract)
(4) MRI OR voxel-based OR structural OR cortical OR morphometric OR morphometry(in title or abstract)

(5) fMRI OR functional connectivity OR functional connection OR regional homogeneity OR BOLD(in title or abstract)

\section{(6) (1)AND(2)AND(3) $\mathrm{OR}(4 \mathrm{OR}(5)$}

Three English databases (PubMed, Web of Science, EmBase) and three Chinese databases (China National Knowledge Infrastructure, Wanfang and China Biology Medicine disc) were queried. Inclusion criteria for eligible literature are as follows: (1) original clinical studies on human; (2) participants included patients diagnosed with $\mathrm{MOH}$ according to International Classification of Headache Disorders (ICHD); (3a) voxel-, volume-based gray matter analyses with $\mathrm{T} 1$ weighted imaging (T1WI) data; (3b) BOLD MRI studies; (3c) PET studies; (4) parameters of neuroimaging acquisition was reported; (5) results were reported using Montreal Neurological Institute (MNI) or Talairach coordinates; (6) studies published in Chinese or English in peer-recognized academic journals. The exclusion criteria of literature were: (1) duplicate reports of an included study; (2) conference reports; (3) studies without a comparing group; (4) single studies that cannot be pooled due to a lack of another matched study using comparable design; (5) studies yielding negative findings in which no coordinate was available.

Literature selection was performed by two neurology researchers, during which disagreement was resolved by the third researcher. Afterwards data from the included studies were extracted into spreadsheets and proofread by a group of researchers. Relevant information that was extracted included: (1) publication information (title, published journal, year of publication), (2) demographic information (number of subjects in each group, gender ratio, average age, handedness), (3) clinical information (diagnostic criteria, course of headache, time of medication overuse, types of overused medication), (4) technical information of neuroimaging (scanning techniques, scanned regions, magnetic field intensity, slice thickness), (5) analyzing methods of imaging data (spatial coordinates of vertices, types of coordinate system, methodology, software used and its version, methods for multiple comparison correction, and the diameter of Gaussian kernel).

\section{Statistical analysis}

We adopted in our statistical analysis the ALE algorithm, a novel quantitative voxel-based method that can be used to estimate consistent change of gray matter (or functional image) from an array of imaging studies which reported peaks of gray matter alteration or functional activation of statistical significance (Laird et al., 2005). ALE requires that 
peak foci of clusters be reported in stereotactic coordinates (in " $\mathrm{x}, \mathrm{y}, \mathrm{z}$ " format). All reported foci were retrieved from articles and imported into the software. ALE approach, the technique of which has been described (Laird et al., 2005; Turkeltaub et al., 2002), models each alteration focus as the center of a spherical Gaussian probability distribution. In the updated version of ALE algorithm (GingerALE 3.0.2 http://brainmap.org) (Eickhoff et al., 2009), all reported foci (coordinates of maximum activation) for a given study are modelled as the peaks of stereotactic Gaussian probability distribution. A "modelled activation" (MA) map is computed, representing a summary of the coordinates from the specific study. ALE values are then calculated on a voxelby-voxel basis by taking the union of these individual MA maps, with higher ALE value indicating more significance in a voxel. This revised analysis tests for convergence between studies (which is random-effects) rather than foci (which is fixed-effects).

Statistical significance of our analysis was assessed with a $P$-threshold corrected for comparisons using the familywise error (FWE) (Eickhoff et al., 2012; Genovese et al., 2002) which is, and an uncorrected $P$ which is more liberal. The results are presented at $P<0.05$ with 1000 permutations FWE corrected for multiple comparisons, and an uncorrected $P<0.001$ set with a minimum cluster volume of 100 $\mathrm{mm}^{3}$. Each thresholded ALE map produced in MNI space was overlaid using MRIcron and MRIcroGL software onto the International Consortium for Brain Mapping(ICBM)-152 template.

\section{Results}

Altogether we identified 927 articles, among which one article was found from reference of reviews, yielding five VBM studies into ALE quantitative synthesis after the inclusion and exclusion criteria were applied (see Fig. 1, Tables 1 and 2). All six identified fMRI studies were unfortunately excluded for they used disparate and incomparable methods of neuroimages statistical processing. The only two PET studies on $\mathrm{MOH}$ did not enter quantitative ALE synthesis for they set different control groups. The flowchart of literature selection following PRISMA statement is shown in Fig. 1. We put into GingerALE a total of 54 coordinates of vertices reported by the five included studies, which constructed two ALE analyses.

Firstly, four studies on gray matter change of $\mathrm{MOH}$ compared with HCs were included in ALE, with 286 subjects and 50 vertices put in. It was reported that increased gray matter density in $\mathrm{MOH}$ patients located in midbrain, striatum, cingulate, inferior parietal cortex and cerebellum $(P<0.001$ uncorrected). On the other hand, decreased gray matter density were reported in orbitofrontal cortex $(P<0.05$, FWE corrected), frontal, insular and parietal cortices $(P<0.001$ uncorrected; see Tables 3 and 4, Figs. 2 and 3).

In another ALE analysis, two studies comparing pre- and post-withdrawal of overused medication were also pooled using ALE. Four coordinates from 58 subjects were put into ALE, which reported that, after detoxification, gray matter density decreased in superior temporal gyrus, cuneus, midbrain and cerebellum $(P<0.001$ uncorrected; see Table 5, Fig. 3).

\section{Discussion}

This research is the first meta-analytic ALE study on $\mathrm{MOH}$ so far. Based on our ALE study on the morphological alteration of $\mathrm{MOH}$ patients, it is confirmed that $\mathrm{MOH}$ is a secondary headache disorder closely associated with changes among multiple brain regions and networks. We observed abnormal gray matter in multiple regions including subcortical nuclei, brain stem and cerebellum. Gray matter of midbrain, cerebellum, cuneus and superior temporal gyrus decreased after detoxification, indicating some of the $\mathrm{MOH}-$ related gray matter increase may be reversible. The ALE method helped us in combining stereotactic coordinates of peaks of gray matter change from $\mathrm{MOH}$ neuroimaging studies, thus revealed that abnormal brain areas related to $\mathrm{MOH}$ are mainly distributed in the pain network, reward system, and the prefrontal area, as are illustrated in Fig. 4.

\section{Alteration in reward system}

Our research showed that $\mathrm{MOH}$ patients have increased gray matter in the bilateral ventral striatum and ventral tegmental area (VTA) gray matter, which indicates that addiction caused by an abnormal reward system constitutes important pathogenesis of $\mathrm{MOH}$. The ventral striatum contains nucleus accumbens, a pivotal dopaminergic area in the brain system related to reward processing. It receives signals from the orbitofrontal gyrus, the anterior cingulate gyrus, and the midbrain (Haber \& Knutson, 2010). Research on non-human primates has identified nucleus accumbens, dorsal striatum, and orbitofrontal cortex are key areas responsible for the regulation of reward. Comfortable stimuli such as food or expectation of benefit activates these brain areas, which then release dopamine. Therefore, the nucleus accumbens is also referred to as the "pleasure center" (Di Chiara, 2002). Functional magnetic resonance imaging studies of adults also observed that the BOLD signal in these areas changes under reward conditions (May et al., 2004). The dysfunction of the reward system is considered to play a crucial role in drug abuse and addiction, for it's been reported that the ventral striatum of patients with cocaine abuse has increased gray matter (Connolly et al., 2013). It is generally believed that 


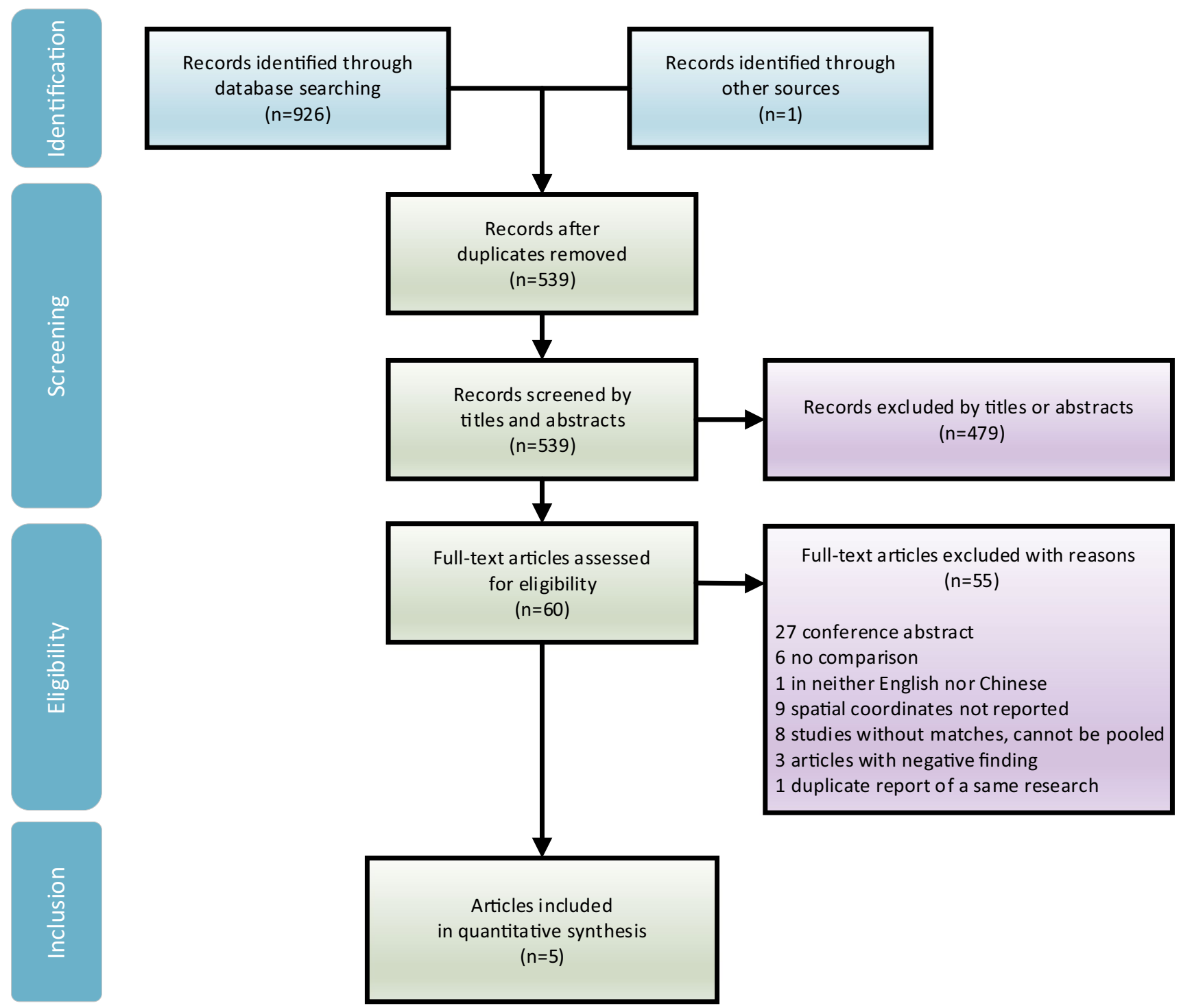

Fig. 1 Literature selection following Preferred Reporting Items for Systematic Reviews and Meta-Analyses flowchart

drugs, which a patient relies on for reasons, can cause dopamine release from VTA by stimulating the $\gamma$-aminobutyric acid A receptors. Then dopaminergic receptors of nucleus accumbens received the signal from VTA and activates the reward system, prompting the patient to take drugs repeatedly. Structural and functional connection between VTA and nucleus accumbens was previously confirmed (Wang et al., 2019). Therefore, the alteration in the ventral striatum and VTA indicates a close connection between the reward system and $\mathrm{MOH}$. Enlarged ventral striatum could work as a biomarker for $\mathrm{MOH}$. Despite this potential association, more neuroimaging evidence is required, for enlarged nucleus accumbens was also found in CM patients (PlanchueloGómez et al., 2020).

Combined with the results of other clinical studies and functional imaging studies, addiction is considered to be proven to be involved in the pathogenesis of $\mathrm{MOH}$. The drug overuse behavior of MOH patients is similar to that of other substance dependence such as drugs. As was estimated that about $2 / 3$ of MOH patients met the diagnostic criteria for drug dependence (DSM-IV) (Radat et al., 2008). Functional MRI discovered brain dopamine system dysfunction in $\mathrm{MOH}$ patients relative to $\mathrm{HCs}$, and it returned to normal after six months of drug withdrawal (Ferraro et al., 2012).

The important pathogenesis of substance addiction of $\mathrm{MOH}$ inspires us to treat $\mathrm{MOH}$ through behavioral intervention. This also corroborates that withdrawal of analgesics and replacement with non-addictive prophylactic medication is effective in relieving pain for most $\mathrm{MOH}$, and preventing medication overuse in patients with other chronic headache who are vulnerable to drug abuse. 
Table 1 Demographic and clinical information of included studies

\begin{tabular}{|c|c|c|c|c|c|c|c|}
\hline Included studies & Number of subjects & $\begin{array}{l}\text { Age (years) } \\
\bar{x} \pm S D\end{array}$ & Male/female & Handedness & $\begin{array}{l}\text { Duration of } \\
\text { headache } \\
\text { (years) }\end{array}$ & $\begin{array}{l}\text { Overused medica- } \\
\text { tion } \\
\text { (number of sub- } \\
\text { jects) }\end{array}$ & $\begin{array}{l}\text { Frequency of anal- } \\
\text { gesics intake (days/ } \\
\text { month) }\end{array}$ \\
\hline $\begin{array}{l}\text { Riederer et al., } \\
2012\end{array}$ & $\begin{array}{l}\text { MOH } 29 \\
\text { Paired HC } 29\end{array}$ & $\begin{array}{l}41.4 \pm 12.7 \\
41.7 \pm 12.8\end{array}$ & $7 / 22$ & Righthanded & $\begin{array}{l}15.1 \pm 11.0 \\
\mathrm{NA}\end{array}$ & $\begin{array}{l}\text { Simple analge- } \\
\text { sics(21), } \\
\text { Combination anal- } \\
\text { gesics(3), } \\
\text { Triptans(20), } \\
\text { Opioids(3) }\end{array}$ & $22.7 \pm 7.7$ \\
\hline Chen et al., 2018 & $\begin{array}{l}\text { MOH } 36 \\
\text { HC } 32\end{array}$ & $\begin{array}{l}42.47 \pm 9.34 \\
41.34 \pm 10.89\end{array}$ & $\begin{array}{l}5 / 31 \\
12 / 20\end{array}$ & Righthanded & $\begin{array}{l}17.81 \pm 5.81 \\
\text { NA }\end{array}$ & Not reported & NA \\
\hline Lai et al., 2016 & $\begin{array}{l}\text { MOH } 33 \\
\text { Paired HC } 33\end{array}$ & $\begin{array}{l}40.2 \pm 10.0 \\
39.7 \pm 11.1\end{array}$ & $6 / 27$ & Righthanded & $18.4 \pm 10.4$ & $\begin{array}{l}\text { NSAIDs(26), } \\
\text { Triptans(1), } \\
\text { Ergotamine(2), } \\
\text { Opioids(2), } \\
\text { Unknown(7) }\end{array}$ & $\begin{array}{l}24.7 \pm 6.65 \\
-\end{array}$ \\
\hline $\begin{array}{l}\text { Mehnert et al., } \\
2018\end{array}$ & $\begin{array}{l}\text { MOH } 18 \\
\text { Paired HC } 18\end{array}$ & $\begin{array}{l}36 \pm 14 \\
34 \pm 9\end{array}$ & $5 / 13$ & Righthanded & $\begin{array}{l}20 \pm 14 \\
-\end{array}$ & $\begin{array}{l}\text { NSAID(12), } \\
\text { Triptans(5), } \\
\text { Both(1) }\end{array}$ & $\begin{array}{l}21 \pm 4 \\
-\end{array}$ \\
\hline $\begin{array}{l}\text { Riederer et al., } \\
2013\end{array}$ & $\begin{array}{l}\text { Effective with- } \\
\text { drawal } 11 \\
\text { Ineffective } \\
\text { withdrawal } 11 \\
\text { (paired) }\end{array}$ & $\begin{array}{l}41.8 \pm 9.1 \\
44.3 \pm 12.0\end{array}$ & $2 / 9$ & Righthanded & $\begin{array}{l}20.1 \pm 12.2 \\
19.0 \pm 10.0\end{array}$ & $\begin{array}{l}\text { Simple analge- } \\
\text { sics(7), } \\
\text { Triptans(6), Com- } \\
\text { binations(9) }\end{array}$ & $\begin{array}{l}6.4 \pm 4.9 \\
12.8 \pm 9.4\end{array}$ \\
\hline
\end{tabular}

$\mathrm{MOH}$ medication overuse headache; $H C$ healthy control; NSAID non-steroidal inflammatory drug; NA not available

Table 2 Technical information of scanning and analyzing methods of imaging data used by included studies

\begin{tabular}{lllll}
\hline Included studies & $\begin{array}{l}\text { Scanning } \\
\text { /magnetic field strength }\end{array}$ & $\begin{array}{l}\text { Statistical Analy- } \\
\text { sis }\end{array}$ & Software & $\begin{array}{l}\text { Correction for } \\
\text { multiple com- } \\
\text { parison }\end{array}$ \\
\hline $\begin{array}{l}\text { Riederer et al., 2012 } \\
\text { Chen et al., 2018 }\end{array}$ & MR T1WI/3 T & VBM & SPM8 & FDR $P<0.05$ \\
& MR T1WI/3 T & VBM & SPM & FDR $P<0.05$ \\
Lai et al., 2016 & MR T1WI/1.5 T & VBM & SPM8 (GLM Flex toolbox) & FWE $P<0.05$ \\
Mehnert et al., 2018 & MR T1WI/3 T & VBM & CAT12 & FWE $P<0.05$ \\
Riederer et al., 2013 & MR T1WI/3 T & VBM & VBM8, SPM8 & FWE $P<0.05$ \\
\hline
\end{tabular}

$M O H$ Medication overuse headache; $H C$ health controls; SPM Statistical Parametric Mapping; FDR false discovery rate; FWE family-wise error; $M R$ magnetic resonance; T1WI T1 weighted image; $V B M$ voxel-based morphometry; FWE family-wise error

\section{Alteration in orbital frontal gyrus}

Our results suggested the presence of gray matter atrophy in prefrontal cortex in $\mathrm{MOH}$ patients, including orbitofrontal cortex (OFC), superior frontal gyrus, middle frontal gyrus, and inferior frontal gyrus. Gray matter atrophy of the orbital gyrus passed FWE correction. Given that gray matter atrophy may indicate neural degeneration or dysfunction, this finding echoes with a previous PET study (Fumal et al., 2006) which found hypometabolism in the orbitofrontal gyrus on $\mathrm{MOH}$ patients relative to $\mathrm{HCs}$.

Firstly, apart from gray matter decrease, there was also convincing evidence based on FDG-PET behavioral and pharmacological studies (London, 2000; Volkow et al., 2004) that OFC plays a vital role in drug addiction, craving, and compulsive behavior, which are associated with abnormally activated striatum-thalamus-orbitofrontal cortex circuit. The abnormality of OFC affects people's expectations and desires, (Schoenbaum \& Roesch, 2005) while weakens decision-making capabilities, for which $\mathrm{MOH}$ patients are more susceptible to essentially ineffective analgesics.

Secondly, OFC is believed to be associated with depression. The VBM study (Webb et al., 2014) found that the severity of depressive symptoms was related to the reduction of gray matter in areas such as OFC. Given that depression and anxiety often co-exist with $\mathrm{MOH}$, we speculate 
Table 3 Brain regions that reported increased gray matter density in $\mathrm{MOH}$ patients compared with healthy controls by GingerALE

\begin{tabular}{|c|c|c|c|c|c|c|}
\hline \multicolumn{6}{|l|}{ Increased gray matter density } & \multirow[t]{3}{*}{ Contributing studies } \\
\hline \multirow[t]{2}{*}{ Brain areas } & \multirow[t]{2}{*}{$\mathrm{BA}^{\mathrm{a}}$} & \multicolumn{3}{|c|}{ MNI coordinates } & \multirow[t]{2}{*}{$\operatorname{ALE}\left(\times 10^{-3}\right)$} & \\
\hline & & $X$ & $\mathrm{Y}$ & $\mathrm{Z}$ & & \\
\hline \multicolumn{7}{|l|}{ Midbrain } \\
\hline PAG & - & 0 & -32 & 12 & 10.05 & Riederer et al., 2012 \\
\hline $\mathrm{L}$ ventral lateral PAG & - & -2 & -32 & -8 & 9.48 & Chen et al., 2018 \\
\hline L Ventral tegmental area & - & 0 & -22 & -12 & 10.20 & Chen et al., 2018 \\
\hline L substantia nigra & - & -8 & -16 & -12 & 10.20 & Chen et al., 2018 \\
\hline $\mathrm{L}$ thalamus & - & -10 & -24 & 2 & 10.05 & Riederer et al., 2012 \\
\hline \multicolumn{7}{|l|}{ Trigeminal root entry zone } \\
\hline L trigeminal root entry zone & - & -20 & -28 & -30 & 9.13 & Chen et al., 2018 \\
\hline $\mathrm{R}$ trigeminal root entry zone & - & 19 & -32 & -29 & 9.47 & Chen et al., 2018 \\
\hline \multicolumn{7}{|l|}{ Striatum } \\
\hline $\mathrm{R}$ ventral striatum/thalamus & - & 10 & -22 & 4 & 10.05 & Riederer et al., 2012 \\
\hline$R$ ventral striatum /substantia nigra & - & 10 & -16 & -12 & 9.83 & Chen et al., 2018 \\
\hline $\mathrm{L}$ ventral striatum & - & -12 & 14 & -8 & 10.05 & Riederer et al., 2012 \\
\hline $\mathrm{R}$ ventral striatum & - & 10 & 18 & -10 & 10.05 & Riederer et al., 2012 \\
\hline L putamen & - & -32 & -12 & -4 & 10.05 & Riederer et al., 2012 \\
\hline \multicolumn{7}{|l|}{ Cingulate $\mathrm{g}$} \\
\hline $\mathrm{R}$ posterior cingulate $\mathrm{g}$ & 31 & 4 & -38 & 30 & 10.05 & Riederer et al., 2012 \\
\hline L middle cingulate $g$ & 24 & -4 & -6 & 36 & 10.05 & Riederer et al., 2012 \\
\hline $\mathrm{R}$ inferior parietal cortex & - & 48 & -76 & 10 & 10.05 & Riederer et al., 2012 \\
\hline \multicolumn{7}{|l|}{ Temporal lobe } \\
\hline \multirow[t]{2}{*}{ L fusiform $\mathrm{g}$} & 37 & -28 & -68 & -12 & 10.05 & Riederer et al., 2012 \\
\hline & 37 & -36 & -16 & -30 & 10.05 & Riederer et al., 2012 \\
\hline $\mathrm{R}$ fusiform $\mathrm{g}$ & 37 & 30 & -64 & -14 & 10.05 & Riederer et al., 2012 \\
\hline L hippocampus & - & -26 & -34 & -4 & 10.05 & Riederer et al., 2012 \\
\hline R hippocampus & - & 26 & -32 & -4 & 10.05 & Riederer et al., 2012 \\
\hline \multicolumn{7}{|l|}{ Cerebellum } \\
\hline $\mathrm{R}$ inferior cerebellum/cerebellar tonsil & - & 34 & -66 & -46 & 10.05 & Riederer et al., 2012 \\
\hline $\mathrm{R}$ inferior cerebellum & - & 44 & -62 & -34 & 10.05 & Riederer et al., 2012 \\
\hline $\mathrm{R}$ inferior cerebellum/ cerebellar tonsil & - & 12 & -56 & -44 & 10.05 & Riederer et al., 2012 \\
\hline $\mathrm{R}$ cerebellar vermis & - & 4 & -52 & -24 & 10.05 & Riederer et al., 2012 \\
\hline $\mathrm{L}$ inferior cerebellum/ cerebellar tonsil & - & -16 & -52 & -46 & 10.05 & Riederer et al., 2012 \\
\hline
\end{tabular}

MNI Montreal Neurological Institute; $L$ left; $R$ right; $g$ gyrus; $A L E$ Activation Likelihood Estimation; $P A G$ periaqueductal gray; $B A$ Brodmann Area

${ }^{a}$ Some of the brain regions are not within a specific Brodmann Area that depression may be a risk factor for overuse of drugs. This may explain why amitriptyline, as an antidepressant, is recommended as a prophylactic medication for migraine. It was found that, for migraineurs who overdose analgesics, amitriptyline can reduce their dosage of analgesics and frequency of headache attacks (Hering \& Steiner, 1991).

Abnormality OFC is widely considered characteristic of MOH (Riederer et al., 2012). Increase of gray matter volume of OFC might predict better treatment response (Lai et al., 2016). Nonetheless, further evidence is required to support such an idea. Two MRI studies (Beckmann et al., 2018; Chanraud et al., 2014) (17MOH vs 17 normal, $27 \mathrm{MOH}$ vs 27 normal, respectively) did not find significant gray matter differences in $\mathrm{MOH}$ comparing to HCs. Another PET study (Di et al., 2013) (10MOH vs 17 normal) reported no significant metabolic change in the orbitofrontal gyrus in $\mathrm{MOH}$ patients. Facing these divergent findings, we need to, on the one hand, pay attention to their relatively small sample sizes that were more susceptible to random errors. In this regard, future neuroimaging studies may require a larger sample size to confirm whether OFC anomalies are consistent in $\mathrm{MOH}$. On the other hand, the prefrontal cortex itself, especially the orbitofrontal gyrus, is involved in a variety of neurological functions. With the help of datadriven Meta-Analytic Connectivity Modeling and using OFC as a seed region of interest, OFC (Zald et al., 2014) 
Table 4 Brain regions that reported decreased gray matter density in $\mathrm{MOH}$ patients compared with healthy controls by GingerALE

\begin{tabular}{|c|c|c|c|c|c|c|}
\hline \multicolumn{6}{|c|}{ Regions with decreased gray matter density } & \multirow[t]{3}{*}{ Contributing studies } \\
\hline \multirow[t]{2}{*}{ Brain areas } & \multirow[t]{2}{*}{$\mathrm{BA}^{\mathrm{b}}$} & \multicolumn{3}{|c|}{ MNI Coordinates } & \multirow{2}{*}{$\begin{array}{l}\text { ALE } \\
\left(\times 10^{-3}\right)\end{array}$} & \\
\hline & & $X$ & $\mathrm{Y}$ & $\mathrm{Z}$ & & \\
\hline \multicolumn{7}{|l|}{ Frontal lobe } \\
\hline $\mathrm{R}$ medial orbital g & 11 & 10 & 48 & -22 & 9.47 & Mehnert et al., 2018 \\
\hline $\mathrm{L}$ medial orbital $\mathrm{g}^{\mathrm{a}}$ & 11 & -12 & 38 & -24 & 18.83 & $\begin{array}{l}\text { Mehnert et al., 2018; Lai } \\
\text { et al., } 2016\end{array}$ \\
\hline R orbital g & 10 & 8 & 66 & -4 & 10.05 & Riederer et al., 2012 \\
\hline $\mathrm{R}$ rectal $\mathrm{g}$ & 11 & 2 & 24 & -26 & 9.45 & Lai et al., 2016 \\
\hline \multirow[t]{2}{*}{ L superior frontal $\mathrm{g}$} & 46 & -2 & 60 & 14 & 9.45 & Lai et al., 2016 \\
\hline & 46 & 28 & 60 & 0 & 10.05 & Riederer et al., 2012 \\
\hline \multirow[t]{2}{*}{$\mathrm{R}$ medial frontal $\mathrm{g}$} & 9 & 3 & 38 & 28 & 8.68 & Riederer et al., 2012 \\
\hline & 9 & 42 & 46 & 18 & 9.11 & Lai et al., 2016 \\
\hline \multirow[t]{2}{*}{$\mathrm{L}$ inferior frontal $\mathrm{g}$} & 47 & -48 & 18 & 2 & 10.05 & Lai et al., 2016 \\
\hline & 47 & -48 & 32 & -10 & 9.80 & Lai et al., 2016 \\
\hline \multirow[t]{2}{*}{$\mathrm{R}$ inferior frontal $\mathrm{g}$} & 47 & 36 & 31 & -20 & 9.80 & Lai et al., 2016 \\
\hline & 47 & 40 & 32 & 12 & 9.47 & Mehnert et al., 2018 \\
\hline $\mathrm{R}$ frontal operculum & 9 & 56 & 17 & 27 & 9.45 & Lai et al., 2016 \\
\hline $\mathrm{L}$ precentral $\mathrm{g}$ & 6 & -30 & -9 & 66 & 9.80 & Lai et al., 2016 \\
\hline $\mathrm{L}$ insula & 13 & -42 & -6 & -6 & 10.05 & Riederer et al., 2012 \\
\hline $\mathrm{R}$ insula & 13 & 44 & 2 & 4 & 10.05 & Riederer et al., 2012 \\
\hline $\mathrm{L}$ precuneus & 7 & 0 & -52 & 52 & 10.06 & Riederer et al., 2012 \\
\hline \multirow[t]{2}{*}{$\mathrm{R}$ precuneus } & 7 & 10 & -62 & 46 & 9.34 & Lai et al., 2016 \\
\hline & 7 & 14 & -54 & 50 & 9.23 & Mehnert et al., 2018 \\
\hline $\mathrm{L}$ superior occipital g/cuneus & 19 & -15 & -98 & 20 & 9.80 & Lai et al., 2016 \\
\hline $\mathrm{R}$ lingual $\mathrm{g}$ & 30 & 5 & -62 & 3 & 9.45 & Lai et al., 2016 \\
\hline R hippocampus & - & 30 & -21 & -9 & 8.82 & Mehnert et al., 2018 \\
\hline L cerebellum & - & -24 & -59 & -62 & 9.80 & Lai et al., 2016 \\
\hline
\end{tabular}

$M N I$ Montreal Neurological Institute; $L$ left; $R$ right; $g$ gyrus; $A L E$ Activation Likelihood Estimation; $P A G$ periaqueductal gray; $B A$ Brodmann Area

${ }^{a}$ Family-wise error corrected, $P<0.05$

${ }^{\mathrm{b}}$ Some of the brain regions are not within a specific Brodmann Area was found with extensive functional connections with multiple brain areas such as the default mode network, and participates in functions such as language, memory, and emotion. Therefore, it can be speculated that OFC alteration may present a relationship with other comorbid neuropsychological disorders. One piece of advice for future MOH-related neuroimaging studies is that subjects' comorbid neuropsychological diseases be more rigorously investigated and controlled as confounding factors, so that more affirmative findings can be obtained.

\section{Alteration in pain network}

Our results suggest that changes in multiple regions associate with the perception of pain. Periaqueductal gray (PAG) and trigeminal afferent area in the midbrain, thalamus and cerebellum, reported gray matter increase in $\mathrm{MOH}$, whereas insula reported gray matter decrease. Notably, the second synthesis shows gray matter in midbrain and cerebellum shrank back after medication was ceased (see Table 5).

Pain processing is recognized as a highly complex process that involves multiple brain areas. After a person is stimulated by pain, cerebral hemodynamic changes and functional MRI activation was observed in the primary and secondary somatosensory cortices, the anterior cingulate gyrus, and the insula, which were thereafter named the pain matrix (Peyron et al., 2000; Porro, 2003). Midbrain PAG, another crucial region of the pain processing network, has been shown to be closely related to the downward inhibition of pain sensing (Millan, 2002). The insular cortex, in which lesion can cause hyperalgesia (Starr et al., 2009), is an anatomical interface between afferent processing and cognitive modulation systems. Our study suggests that $\mathrm{MOH}$ is closely related to a reversible modification in pain network. There were also functional evidence supporting such finding 


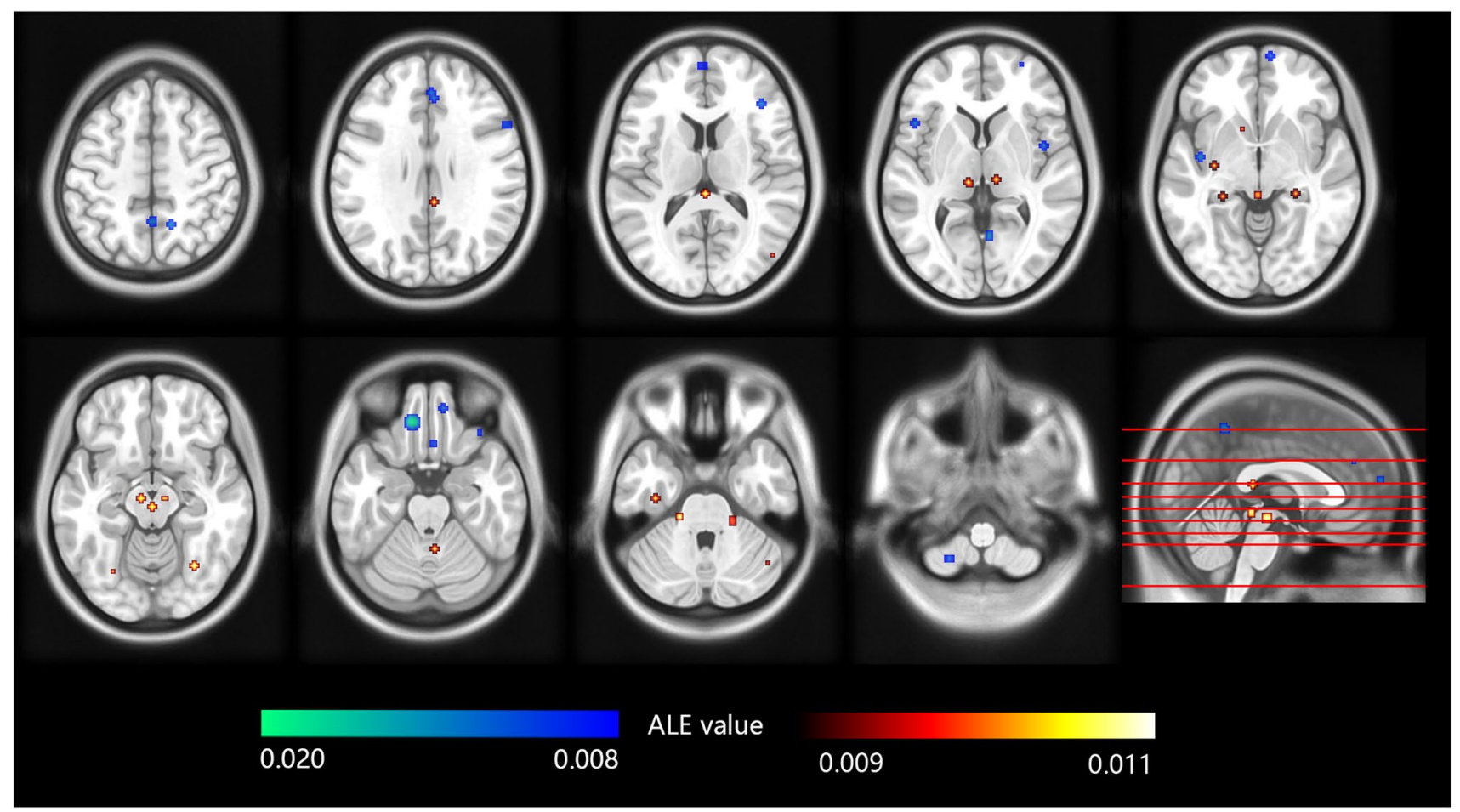

Fig. 2 Brain regions that reported increased or decreased gray matter density in $\mathrm{MOH}$ patients compared with healthy controls by GingerALE. The color bars indicate ALE value of clusters. Red-yellow indicates increased gray matter density, while blue-indigo indicates decreased gray matter density. The left of the graph corresponds to the left side of patients

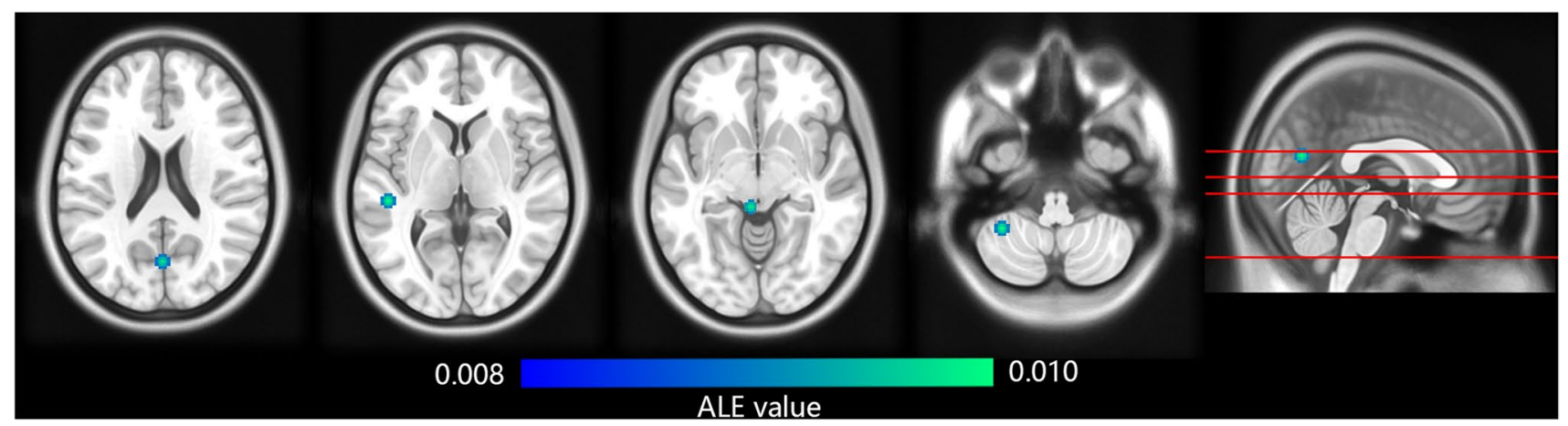

Fig. 3 Brain regions that reported decreased gray matter density in detoxified MOH patients compared with baseline by GingerALE. The color bar indicates ALE value of clusters. The left of the graph corresponds to the left side of patients

Table 5 Reported brain regions with decreased gray matter density in detoxified $\mathrm{MOH}$ patients compared with baseline by GingerALE

\begin{tabular}{|c|c|c|c|c|c|c|}
\hline \multirow[t]{2}{*}{ Brain areas } & \multirow[t]{2}{*}{$\mathrm{BA}^{\mathrm{a}}$} & \multicolumn{3}{|c|}{ MNI coordinates } & \multirow{2}{*}{$\begin{array}{l}\text { ALE } \\
\left(\times 10^{-3}\right)\end{array}$} & \multirow[t]{2}{*}{ Contributing studies } \\
\hline & & $\mathrm{X}$ & $\mathrm{Y}$ & $\mathrm{Z}$ & & \\
\hline L superior temporal $\mathrm{g}$ & 22 & -48 & -30 & 3 & 9.47 & Mehnert et al., 2018 \\
\hline L cuneus & 17 & 0 & -70 & 18 & 9.14 & Mehnert et al., 2018 \\
\hline L midbrain & - & -5 & -34 & -8 & 8.33 & Riederer et al., 2013 \\
\hline
\end{tabular}

$M N I$ Montreal Neurological Institute; $L$ left; $g$ gyrus; ALE Activation Likelihood Estimation; $B A$ Brodmann Area

${ }^{a}$ Some of the brain regions are not within a specific Brodmann Area 


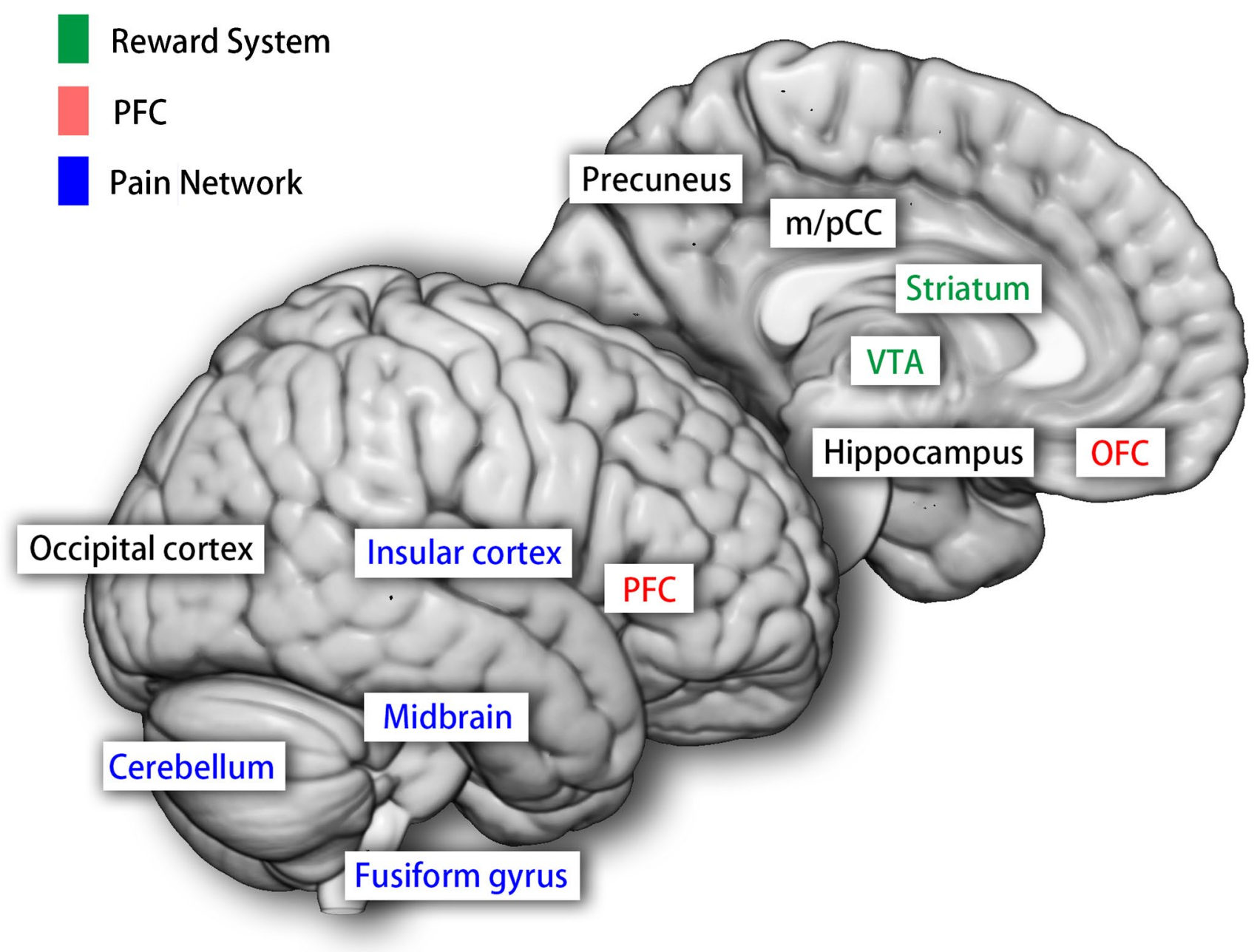

Fig. 4 Illustration of altered networks discovered by meta-analytical activation likelihood estimation on gray matter alteration in medication overuse headache patients. PFC, prefrontal cortex; OFC, orbito-

(Grazzi et al., 2010). Nonetheless, gray matter hyperplasia in the midbrain may not be unique to $\mathrm{MOH}$, since it is also present in migraine (May, 2009). To better demonstrate the effect of medication overuse, further comparative studies between $\mathrm{MOH}$ and other primary headache disorders are in need, such as episodic migraine, which is less associated with drug abuse.

Moreover, our research confirms that $\mathrm{MOH}$ is also closely linked to cerebellar gray matter increase, which normalized after analgesics withdrawal. Meanwhile, PET study observed increased glucose metabolism in the cerebellar vermis in $\mathrm{MOH}$ that also normalized after analgesic withdrawal (Fumal et al., 2006). Cerebellum is found to be involved in pain perception and cognition by neuro-anatomic studies. In animal experiment, it was found that pure C-fiber reached the cerebellum (Jie \& Pei-Xi, 1992). Such association between MOH and cerebellum was frontal cortex; VTA, ventral tegmental area; m/pCC, middle/posterior cingulate cortex

also supported by fMRI evidence. Compared with normal controls, there was a significantly enhanced functional connectivity between the left cerebellar hemisphere and the midbrain peri-aqueduct gray matter in $\mathrm{MOH}$ patient (Michels et al., 2017). Clinical study showed that patients in the recovery period of cerebellar infarction are more sensitive and severer to mechanical and thermal stimulation than normal people (Ruscheweyh et al., 2014).

Besides, due to insufficient functional neuroimaging studies on MOH, ALE analysis with either fMRI or PET was not feasible, despite their significant neurological value. Nevertheless, available studies found that $\mathrm{MOH}$ reported functional change in the pain network comparing to HCs. Multiple functional connectivity abnormalities was found in the trigeminal spinal tract nucleus, operculum, secondary somatosensory cortex (Mehnert et al., 2018). Hypermetabolism in insula was reported (Di et al., 2013). 


\section{Conclusions}

This meta-analytic ALE confirmed that $\mathrm{MOH}$ is associated with morphologic alteration in the reward system, the prefrontal cortex and a reversible modification in the pain network. Further functional imaging paradigms and longitudinal studies are required for a more definite conclusion and a causal mechanism.

\section{Limitations and prospects}

Our study is limited by insufficient data available. Original neuroimaging studies on $\mathrm{MOH}$ included are few. One reason for this is that divergence in imaging data analysis techniques shrank the number of studies that can be combined. As an example, rest-state BOLD-based fMRI alone can be analyzed by rest-state-based amplitude of low frequency fluctuation(ALFF), ReHo, whole brain independent component analysis(ICA), and region of interest(ROI)-based functional connection, functional connection density(FCD), not to mention tasks-based fMRI studies. Limited number of comparable studies weakens the power of conclusion and brings out another limitation that most results are presented with uncorrected $P<0.001$. Although uncorrected coordinates are supported by only one study, the pooled results may reflect a more generalized pattern after combining findings from different studies.

From the prospective the control selection, we identified only two studies comparing detoxified headache patients with $\mathrm{MOH}$. More similar studies may help distinguishing reversibility in cortical alterations. Furthermore, few studies compared $\mathrm{CM}$ versus $\mathrm{MOH}$. CM patients are susceptible to MO, thus constituting the major type of primary headache disorder of $\mathrm{MOH}$. Some of the altered brain regions, e.g. enlarged nucleus accumbens (May, 2009; PlanchueloGómez et al., 2020) and structural alteration in orbitofrontal gyrus (Mehnert et al., 2018; Planchuelo Gómez et al., 2021), are shared by both $\mathrm{CM}$ and $\mathrm{MOH}$. To observe the sole neural impact associated with medication overuse, more studies comparing $\mathrm{CM}$ with $\mathrm{MOH}$ is needed.

Notably, overused medication could provide crucial information. The comparisons between pre- versus postwithdrawal of medications, and MOH versus chronic headaches (e.g. migraine), may also be invaluable, for they may demonstrate the effect of medication overuse specifically. Although such pooling was infeasible due to limited articles, it is critical in explaining the unique pathophysiology of $\mathrm{MOH}$. In addition, overused medications were diverse and overlapping in the included studies, so we were not able to perform subgroup analysis on types of drugs. To explore respective patterns of grey matter alterations according to overused drugs may be useful in elucidating $\mathrm{MOH}$ pathogenesis because pharmacology of different medication, e.g. migraine-specific ergots and triptans, opioids, and antiinflammatory drugs, may indicate pathogenesis of $\mathrm{MOH}$. For example, anti-CGRP monoclonal antibody, which cannot pass blood brain barrier, proved effective on $\mathrm{MOH}$ (SunEdelstein et al., 2021), implying that peripheral trigeminal nociceptor activation is a crucial mechanism in maintaining the headache in $\mathrm{MOH}$.

We also found that the sample size of most neuroimaging studies was insufficient. It's worth noting that all five included studies had sample sizes of less than 40 per group, which could bring in considerable random error and undermined the stability of the results, impairing the quality and reliability of conclusion.

Furthermore, given that $\mathrm{MOH}$ is a chronic disease, neuroimaging paradigms may also focus on ictal periods, so as to capture neuropathological activities during headache attacks. Notably, studies published so far are mostly in case-control design, which cannot prove causality. We have not identified any temporal study observing how chronic headaches develops into $\mathrm{MOH}$, and how these neuroimaging changes occur. Longitudinal or cohort studies may hopefully disperse the mist clouding the pathogenesis of $\mathrm{MOH}$.

In addition, acupuncture, a non-pharmaceutical treatment for chronic headaches, is worth research attention. It was reported that acupuncture could decrease the mean monthly number of moderate/severe migraine days compared with topiramate (Yang et al., 2011). Being a prophylactic measure, acupuncture may benefit $\mathrm{MOH}$ patients in both medication cessation and pain relief. There have been a variety of neuroimaging studies on the effects of acupuncture on primary headaches, but not on $\mathrm{MOH}$ yet.

In terms of morphometrics, cortical thickness (CT) and local gyrification index (LGI) calculation are also informative gray matter morphometrics. They may supplement VBM from a surface-based prospective. One study, which compared CT and LGI of MOH brains with healthy ones, found reduced CT in the left prefrontal cortex. Also, higher LGI was observed in fusiform gyrus and right occipital pole, the latter of which predicted poor response after detoxification.

Regarding the statistical methodology of ALE, given the coordinate-based data requires only the peaks of altered brain regions. The volume, shapes and sizes of the regions depicted in the original study are omitted, even though they contain valuable information. Furthermore, unlike the traditional META analysis, the ALE method is unable to incorporate negative findings (i.e. studies reporting no group-wise difference, yielding zero vertex) into the statistical analysis. Such negative reports, if included in the algorithm, may improve the comprehensiveness of our ALE results. 
Last but not least, the interpretation of neuroimaging findings requires more evidence. The histological implication of gray matter alteration is so far uncertain and even controversial. It was found that the reduction of brain gray matter in patients with fibromyalgia is not accompanied by damage to the structural or functional integrity of neurons (Pomares et al., 2017). The increase in gray matter can be explained by the up-regulation of GABA receptors and possible inflammatory edema, rather than neuron increase. Interpreting brain gray matter reduction as neuronal damage or synaptic loss lacked cytohistologic evidence (May, 2009). Therefore, cytohistologic methods, electro-encephalogram, other modalities of MRI including magnetic resonance spectroscopy and diffusion tensor imaging, are much needed for a deeper understanding into $\mathrm{MOH}$.

Authors' contributions Study conception and design: Li, Chen. Literature selection, data collection: $\mathrm{Li}$, Chen. Proofreading: Chen, $\mathrm{Li}$, Hou, Jia. Statistical analysis: Chen, Jia. Interpretation of results: Li, Hou. Study supervision: Li. All authors contributed to and approved the final manuscript.

Funding This research was funded by the grant Special Research Fund for Chinese Medicine Research (YN2015MS22) from Guangdong Provincial Hospital of Chinese Medicine.

Data availability All data and materials that support this manuscript are available at request.

Code availability Software used in this research is publicly available.

\section{Declarations}

Ethics approval Not applicable.

Consent to participate Not applicable.

Consent for publication All authors consent to the publication of this manuscript.

Competing Interest None of the authors has any conflict of interest to declare.

Open Access This article is licensed under a Creative Commons Attribution 4.0 International License, which permits use, sharing, adaptation, distribution and reproduction in any medium or format, as long as you give appropriate credit to the original author(s) and the source, provide a link to the Creative Commons licence, and indicate if changes were made. The images or other third party material in this article are included in the article's Creative Commons licence, unless indicated otherwise in a credit line to the material. If material is not included in the article's Creative Commons licence and your intended use is not permitted by statutory regulation or exceeds the permitted use, you will need to obtain permission directly from the copyright holder. To view a copy of this licence, visit http://creativecommons.org/licenses/by/4.0/.

\section{References}

Ayzenberg, I., Obermann, M., Nyhuis, P., Gastpar, M., Limmroth, V., Diener, H. C., Kaube, H., \& Katsarava, Z. (2006). Central sensitization of the trigeminal and somatic nociceptive systems in medication overuse headache mainly involves cerebral supraspinal structure. Cephalalgia, 26(9), 1106-1114. https://doi.org/10. 1111/j.1468-2982.2006.01183.x

Beckmann, Y., Gokce, S., Zorlu, N., Ture, H. S., \& Gelal, F. (2018). Longitudinal assessment of gray matter volumes and white matter integrity in patients with medication-overuse headache. Journal of Neuroradiology, 31(2), 150-156. https://doi.org/10.1177/19714 00918756374

Cevoli, S., Giannini, G., Favoni, V., Terlizzi, R., Sancisi, E., Nicodemo, M., Zanigni, S., Bacchi, R. M., Pierangeli, G., \& Cortelli, P. (2017). Treatment of withdrawal headache in patients with medication overuse headache: A pilot study. Journal of Headache and Pain, 18(1), 56. https://doi.org/10.1186/s10194-017-0763-9

Chanraud, S., Di Scala, G., Dilharreguy, B., Schoenen, J., Allard, M., \& Radat, F. (2014). Brain functional connectivity and morphology changes in medication-overuse headache: Clue for dependencerelated processes? Cephalalgia, 34(8), 605-615. https://doi.org/ 10.1177/0333102413519514

Chen, Z. Y., Chen, X. Y., Liu, M. Q., Ma, L., \& Yu, S. Y. (2018). Volume gain of brainstem on medication-overuse headache using voxel-based morphometry. Chinese Medical Journal, 131(18), 2158-2163. https://doi.org/10.4103/0366-6999.240807

Connolly, C. G., Bell, R. P., Foxe, J. J., \& Garavan, H. (2013). Dissociated grey matter changes with prolonged addiction and extended abstinence in cocaine users. PLoS ONE, 8(3), e59645. https://doi. org/10.1371/journal.pone.0059645

De Felice, M., Ossipov, M. H., Wang, R., Lai, J., Chichorro, J., Meng, I., Dodick, D. W., Vanderah, T. W., Dussor, G., \& Porreca, F. (2009). Triptan-induced latent sensitization: A possible basis for medication overuse headache. Annals of Neurology, 67(3), 325. https://doi.org/10.1002/ana.21897

Di Chiara, G. (2002). Nucleus accumbens shell and core dopamine: Differential role in behavior and addiction. Behabioural Brain Research, 137(1), 75-114. https://doi.org/10.1016/S01664328(02)00286-3

Di, W., Shi, X., Zhu, Y., Tao, Y., Qi, W., Luo, N., Xiao, Z., Yi, C., Miao, J., Zhang, A., Zhang, X., \& Fang, Y. (2013). Overuse of paracetamol caffeine aspirin powders affects cerebral glucose metabolism in chronic migraine patients. European Journal of Neurology, 20(4), 655-662. https://doi.org/10.1111/ene.12018

Diener, H., \& Limmroth, V. (2004). Medication-overuse headache: A worldwide problem. Lancet Neurology, 3(8), 475-483. https://doi. org/10.1016/S1474-4422(04)00824-5

Eickhoff, S. B., Laird, A. R., Grefkes, C., Wang, L. E., Zilles, K., \& Fox, P. T. (2009). Coordinate-based activation likelihood estimation meta-analysis of neuroimaging data: A random-effects approach based on empirical estimates of spatial uncertainty. Human Brain Mapping, 30(9), 2907-2926. https://doi.org/10.1002/hbm.20718

Eickhoff, S. B., Bzdok, D., Laird, A. R., Kurth, F., \& Fox, P. T. (2012). Activation likelihood estimation meta-analysis revisited. NeuroImage, 59(3), 2349-2361. https://doi.org/10.1016/j.neuroimage. 2011.09.017

Ferraro, S., Grazzi, L., Muffatti, R., Nava, S., Ghielmetti, F., Bertolino, N., Mandelli, M. L., Visintin, E., Bruzzone, M. G., Nigri, A., Epifani, F., Bussone, G., \& Chiapparini, L. (2012). In medication-overuse headache, fMRI shows long-lasting dysfunction in midbrain areas. Headache, 52(10), 1520-1534. https://doi.org/10. 1111/j.1526-4610.2012.02276.x 
Fumal, A., Laureys, S., Di Clemente, L., Boly, M., Bohotin, V., Vandenheede, M., Coppola, G., Salmon, E., Kupers, R., \& Schoenen, J. (2006). Orbitofrontal cortex involvement in chronic analgesicoveruse headache evolving from episodic migraine. Brain, $129(\mathrm{Pt}$ 2), 543-550. https://doi.org/10.1093/brain/awh691

Genovese, C. R., Lazar, N. A., \& Nichols, T. (2002). Thresholding of Statistical Maps in Functional Neuroimaging Using the False Discovery Rate. NeuroImage, 15(4), 870-878. https://doi.org/10. 1006/nimg.2001.1037

Grazzi, L., Chiapparini, L., Ferraro, S., Usai, S., Andrasik, F., Mandelli, M. L., Bruzzone, M. G., \& Bussone, G. (2010). Chronic migraine with medication overuse pre-post withdrawal of symptomatic medication: Clinical results and FMRI correlations. Headache, 50(6), 998-1004. https://doi.org/10.1111/j.1526-4610.2010.01695.x

Haber, S. N., \& Knutson, B. (2010). The reward circuit: Linking primate anatomy and human imaging. Neuropsychopharmacology, 35(1), 4-26. https://doi.org/10.1038/npp.2009.129

Headache Classification Committee of the International Headache Society. (2018). The international classification of headache disorders, 3rd edition (ICHD-3). Cephalalgia, 38(1), 1-211. https:// doi.org/10.1177/0333102417738202

Hering, R., \& Steiner, T. J. (1991). Abrupt outpatient withdrawal of medication in analgesic-abusing migraineurs. Lancet, 337(8755), 1442-1443. https://doi.org/10.1016/0140-6736(91)93129-w

James, S. L., Abate, D., Abate, K. H., et al. (2018). Global, regional, and national incidence, prevalence, and years lived with disability for 354 diseases and injuries for 195 countries and territories, 1990-2017: A systematic analysis for the Global Burden of Disease Study 2017. Lancet, 392(10159), 1789-1858. https://doi.org/ 10.1016/S0140-6736(18)32279-7

Jie, W., \& Pei-Xi, C. (1992). Discharge response of cerebellar Purkinje cells to stimulation of C-fiber in cat saphenous nerve. Brain Research, 581(2), 269.

Lai, T., Chou, K., Fuh, J., Lee, P., Kung, Y., Lin, C., \& Wang, S. (2016). Gray matter changes related to medication overuse in patients with chronic migraine. Cephalalgia, 36(14), 1324-1333. https://doi.org/10.1177/0333102416630593

Laird, A. R., Fox, P. M., Price, C. J., Glahn, D. C., Uecker, A. M., Lancaster, J. L., Turkeltaub, P. E., Kochunov, P., \& Fox, P. T. (2005). ALE meta-analysis: Controlling the false discovery rate and performing statistical contrasts. Human Brain Mapping, 25(1), 155-164. https://doi.org/10.1002/hbm.20136

London, E. D. (2000). Orbitofrontal cortex and human drug abuse: Functional imaging. Cerebral Cortex, 10(3), 334-342. https://doi. org/10.1093/cercor/10.3.334

May, A. (2009). Morphing voxels: The hype around structural imaging of headache patients. Brain, 132(Pt 6), 1419-1425. https://doi.org/ 10.1093/brain/awp116

May, J. C., Delgado, M. R., Dahl, R. E., Stenger, V. A., Ryan, N. D., Fiez, J. A., \& Carter, C. S. (2004). Event-related functional magnetic resonance imaging of reward-related brain circuitry in children and adolescents. Biological Psychiatry, 55(4), 359-366. https://doi.org/10.1016/j.biopsych.2003.11.008

Mehnert, J., Hebestreit, J., \& May, A. (2018). Cortical and subcortical alterations in medication overuse headache. Frontiers in Neurology. https://doi.org/10.3389/fneur.2018.00499

Michels, L., Christidi, F., Steiger, V. R., Sándor, P. S., Gantenbein, A. R., Landmann, G., Schreglmann, S. R., Kollias, S., \& Riederer, F. (2017). Pain modulation is affected differently in medicationoveruse headache and chronic myofascial pain - A multimodal MRI study. Cephalalgia, 37(8), 764-779. https://doi.org/10.1177/ 0333102416652625

Millan, M. J. (2002). Descending control of pain. Progress in Neurobiology, 66(6), 355-474. https://doi.org/10.1016/s0301-0082(02) 00009-6
Peyron, R., Laurent, B., \& García-Larrea, L. (2000). Functional imaging of brain responses to pain. A review and meta-analysis. Neurophysiologie Clinique/Clinical Neurophysiology, 30(5), 263-288. https://doi.org/10.1016/S0987-7053(00)00227-6

Planchuelo Gómez, Á., García Azorín, D., Guerrero, Á. L., Aja Fernández, S., Rodríguez, M., \& Luis García, R. (2021). Multimodal fusion analysis of structural connectivity and gray matter morphology in migraine. Human Brain Mapping, 42(4), 908-921. https://doi.org/10.1002/hbm.25267

Planchuelo-Gómez, Á., García-Azorín, D., Guerrero, Á. L., Rodríguez, M., Aja-Fernández, S., \& de Luis-García, R. (2020). Gray matter structural alterations in chronic and episodic migraine: A morphometric magnetic resonance imaging study. Pain Medicine, 21(11), 2997-3011. https://doi.org/10.1093/pm/pnaa271

Pomares, F. B., Funck, T., Feier, N. A., Roy, S., Daigle-Martel, A., Ceko, M., Narayanan, S., Araujo, D., Thiel, A., Stikov, N., Fitzcharles, M. A., \& Schweinhardt, P. (2017). Histological underpinnings of grey matter changes in fibromyalgia investigated using multimodal brain imaging. Journal of Neuroscience, 37(5), 1090-1101. https://doi.org/10.1523/JNEUROSCI.2619-16.2016

Porro, C. A. (2003). Functional imaging and pain: Behavior, perception, and modulation. The Neuroscientist, 9(5), 354-369. https:// doi.org/10.1177/1073858403253660

Radat, F., Creac'H, C., Guegan-Massardier, E., Mick, G., Guy, N., Fabre, N., Giraud, P., Nachit-Ouinekh, F., \& Lanteri-Minet, M. (2008). Behavioral dependence in patients with medication overuse headache: A cross-sectional study in consulting patients using the DSM-IV criteria. Headache, 48(7), 1026-1036. https://doi. org/10.1111/j.1526-4610.2007.00999.x

Reuter, U., Salomone, S., Ickenstein, G. W., \& Waeber, C. (2004). Effects of chronic sumatriptan and zolmitriptan treatment on 5-HT receptor expression and function in rats. Cephalalgia, 24(5), 398407. https://doi.org/10.1111/j.1468-2982.2004.00683.x

Riederer, F., Marti, M., Luechinger, R., Lanzenberger, R., Von Meyenburg, J., Gantenbein, A. R., Pirrotta, R., Gaul, C., Kollias, S., \& Sándor, P. S. (2012). Grey matter changes associated with medication-overuse headache: Correlations with disease related disability and anxiety. World Journal of Biological Psychiatry, 13(7), 517-525. https://doi.org/10.3109/15622975.2012.665175

Riederer, F., Gantenbein, A. R., Marti, M., Luechinger, R., Kollias, S., \& Sándor, P. S. (2013). Decrease of gray matter volume in the midbrain is associated with treatment response in medicationoveruse headache: Possible influence of orbitofrontal cortex. Journal of Neuroscience, 33(39), 15343-15349. https://doi.org/ 10.1523/JNEUROSCI.3804-12.2013

Ruscheweyh, R., Kuhnel, M., Filippopulos, F., Blum, B., Eggert, T., $\&$ Straube, A. (2014). Altered experimental pain perception after cerebellar infarction. Pain, 155(7), 1303-1312. https://doi.org/10. 1016/j.pain.2014.04.006

Schoenbaum, G., \& Roesch, M. (2005). Orbitofrontal cortex, associative learning, and expectancies. Neuron, 47(5), 633-636. https:// doi.org/10.1016/j.neuron.2005.07.018

Starr, C. J., Sawaki, L., Wittenberg, G. F., Burdette, J. H., Oshiro, Y., Quevedo, A. S., \& Coghill, R. C. (2009). Roles of the insular cortex in the modulation of pain: Insights from brain lesions. Journal of Neuroscience, 29(9), 2684-2694. https://doi.org/10.1523/jneur osci.5173-08.2009

Sun-Edelstein, C., Rapoport, A. M., Rattanawong, W., \& Srikiatkhachorn, A. (2021). The evolution of medication overuse headache: History, pathophysiology and clinical update. CNS Drugs, 35(5), 545-565. https://doi.org/10.1007/s40263-021-00818-9

Turkeltaub, P. E., Eden, G. F., Jones, K. M., \& Zeffiro, T. A. (2002). Meta-analysis of the functional neuroanatomy of single-word reading: Method and validation. Neuroimage, 16(3, Part A), 765-780. https://doi.org/10.1006/nimg.2002.1131 
Turkeltaub, P. E., Eickhoff, S. B., Laird, A. R., Fox, M., Wiener, M., \& Fox, P. (2012). Minimizing within-experiment and within-group effects in activation likelihood estimation meta-analyses. Human Brain Mapping, 33(1), 1-13. https://doi.org/10.1002/hbm.21186

Volkow, N. D., Fowler, J. S., \& Wang, G. J. (2004). The addicted human brain viewed in the light of imaging studies: Brain circuits and treatment strategies. Neuropharmacology, 47(Suppl 1), 3-13. https://doi.org/10.1016/j.neuropharm.2004.07.019

Wang, R., Li, M., Zhao, M., Yu, D., Hu, Y., Wiers, C. E., Wang, G., Volkow, N. D., \& Yuan, K. (2019). Internet gaming disorder: Deficits in functional and structural connectivity in the ventral tegmental area-Accumbens pathway. Brain Imaging and Behavior, 13(4), 1172-1181. https://doi.org/10.1007/s11682-018-9929-6

Webb, C. A., Weber, M., Mundy, E. A., \& Killgore, W. D. S. (2014). Reduced gray matter volume in the anterior cingulate, orbitofrontal cortex and thalamus as a function of mild depressive symptoms: A voxel-based morphometric analysis. Psychological Medicine, 44(13), 2833-2843. https://doi.org/10.1017/S0033 291714000348
Westergaard, M. L., Glümer, C., Hansen, E. H., \& Jensen, R. H. (2014). Prevalence of chronic headache with and without medication overuse: Associations with socioeconomic position and physical and mental health status. Pain, 155(10), 2005-2013. https://doi.org/ 10.1016/j.pain.2014.07.002

Yang, C. P., Chang, M. H., Liu, P. E., Li, T. C., Hsieh, C. L., Hwang, K. L., \& Chang, H. H. (2011). Acupuncture versus topiramate in chronic migraine prophylaxis: A randomized clinical trial. Cephalalgia, 31(15), 1510-1521. https://doi.org/10.1177/03331 02411420585

Zald, D. H., McHugo, M., Ray, K. L., Glahn, D. C., Eickhoff, S. B., \& Laird, A. R. (2014). Meta-analytic connectivity modeling reveals differential functional connectivity of the medial and lateral orbitofrontal cortex. Cerebral Cortex, 24(1), 232-248. https://doi.org/ $10.1093 /$ cercor/bhs308

Publisher's note Springer Nature remains neutral with regard to jurisdictional claims in published maps and institutional affiliations. 